\title{
The relationship between the perception of reduced performance due to injury or illness and basic psychological need satisfaction in Norwegian youth elite handball: a cross-lagged panel analysis
}

Siv Gjesdal ${ }^{1}$, Christian Thue Bjørndal ${ }^{1}$ \& Live Steinnes Luteberget

${ }^{1}$ The Norwegian School of Sport Sciences (NIH)

Corresponding author: Siv Gjesdal

E-mail: sivg@nih.no

\section{Abstract}

This study investigated the relationship between perceived reduction in performance due to injury or illness (RPII) and basic psychological need satisfaction in youth elite handball. Participants were 174 elite youth handball players between 15 to 18 years of age, from five different sport schools. It was a quantitative study, with two time points (one week apart), resulting in a crossed-lagged structural equation model. Competence and relatedness satisfaction were found invariant across the two time points, autonomy was not. The structural model showed good fit $\left(\left(\mathrm{S}-\mathrm{B} \mathrm{X}^{2}\right)=[\mathrm{df}=130\right.$, $\mathrm{N}=174]=182.327, p<.0017 ; \mathrm{CFI}=.96 ; \mathrm{RMSEA}=.05[.03-.06]$, and SRMR $=.08)$. Competence $(\beta=.64,95 \% \mathrm{CI}: .51$, $.76)$, relatedness $(\beta=.77,95 \% \mathrm{CI}: .66, .88)$ and RPII $(\beta=.51,95 \% \mathrm{CI}: .37, .66)$ showed moderate temporal stability. When accounting for previous levels of the basic psychological needs, RPII negatively predicted competence $(\beta=-.20$, $95 \% \mathrm{CI}:-.35, .83)$ and relatedness $(\beta=-.16,95 \% \mathrm{CI}:-.30,-.01)$. Taken together, these findings suggest that experiencing RPII can have implications for basic psychological need satisfaction in youth elite handball, showing that factors other than psychosocial ones may play a role therein.

Keywords: motivation, health behavior, older adult physical activity, physical activity

According to self-determination theory (SDT: Deci \& Ryan, 2000), all humans have three innate psychological needs, namely the need for autonomy, competence and relatedness. The need for autonomy refers to perceiving self-endorsement, integration and freedom. The need for competence relates to the perception of mastery and effective interaction with the environment, whilst the need for relatedness is experiencing support, belonging, and security with others. All three needs are considered essential, which means none can be neglected or thwarted without negative consequences for optimal human development and well-being (Ryan \& Deci, 2017). In the context of sport, considerable research has supported a link between the satisfaction of these three needs and positive outcomes, such as positive affect (Adie, Duda, \& Ntoumanis, 2012), performance (Sheldon, Zhaoyang, \& Williams, 2013) and engagement (T. Curran, Hill, Ntoumanis, Hall, \& Jowett, 2016).

Most studies investigating basic psychological needs focus on the influence of the psychosocial environment, mainly the coach (T. Curran et al., 2016; Mageau \& Vallerand, 2003). However, as it is central to SDT that an individual's experiences within a given context are related to their basic psychological need satisfaction in that context, it is likely that other factors in addition to the psychosocial environment can influence need satisfaction (Ryan \& Deci, 2017). One such factor that is highly relevant to the world of sport is experiencing some level of injury or illness (Bjørndal, Andersen, \& Ronglan, 2018; Møller et al., 2017).

The potential implications an injury or illness may have for athletes' basic psychological need satisfaction have not received much attention in the sport science literature. Instead, research has mainly focused on outcomes such as mood states, self-esteem and cognitive appraisals (Smith, 1996; Wiese-Bjornstal, 2010). Specifically, experiencing an injury has been associated with, among others, lowered self-esteem, decreased mood, goal adjustment and a sense of loss. Given that basic psychological need satisfaction has been linked to selfperceptions and affective states in youth sport (Adie et al., 2012; Kipp \& Weiss, 2013), this may be a mechanism to explain why injury or illness incidents can lead to these negative outcomes. Furthermore, investigating whether experiencing an injury can lead to a reduction in basic psychological need satisfaction is particularly relevant in light of more recent studies showing that autonomy, competence and relatedness may be essential to athletes' recovery from such incidents (Ardern, Taylor, Feller, \& Webster, 2013).

Experiencing an injury or illness may impact athletes' need satisfaction by keeping them out of training and/or competition, or by influencing their level of performance, leading to a sense of reduced performance due to an external event, not ability per se. The aim of this study was, therefore, to investigate the relationship between perceived reduced performance due to injury or illness (RPII) and basic psychological need satisfaction. The relationship with competence appears intuitive. If one cannot participate fully, the feeling of mastery is likely to be reduced. The link to relatedness less so, but it is conceivable that partaking at full capacity is important to feel connected to others and that a good performance within a team setting may bring teammates closer together. In terms of autonomy, it could 
be that when reduced performance is the result of an injury or illness, the level of autonomy is impacted due to it being an external event affecting the athlete. Unfortunately, to our knowledge, no study has investigated these relationships specifically. However, previous research has shown that objective performance during a recreational basketball game was positively associated with athletes' sense of competence and relatedness post game (Sheldon et al., 2013). This indicates that aspects related to performance can present immediate consequences for basic psychological need satisfaction.

Although our focus is on need satisfaction as an outcome, we want to acknowledge that it may also be an antecedent of RPII. Indeed, a recent study by Li, Ivarsson, Lam, and Sun (2019) showed that basic psychological need satisfaction negatively predicted injuries in university athletes. The authors offered two potential explanations for this link. First, basic need satisfaction is seen as a coping resource that reduces injury risk through a reduction in stress responses (Quested et al., 2011). Second, need satisfaction is associated with motivational and emotional outcomes that have been negatively linked to injury risk, such as psychological well-being (Adie et al., 2012; Williams \& Andersen, 1998). Combined, this suggests that athletes who feel competent, autonomous and supported by others may be less likely to experience an injury or illness. Moreover, we would argue that the coping resource that need satisfaction represents, coupled with the associated positive outcomes, may also make athletes less likely to interpret injury or illness incidences as a reduction in performance. Accordingly, we also wanted to test basic need satisfaction as a potential antecedent of RPII.

Handball is a physically demanding, high-intensity team sport, characterized by high-intensity actions, such as sprints, accelerations, changes of direction, throws, and frequent physical contact between players (Luteberget \& Spencer, 2017; Póvoas et al., 2014), resulting in a high risk of both acute and chronic injuries (Andersson, Bahr, Clarsen, \& Myklebust, 2018; Asker et al., 2018; Myklebust, 2014; Møller et al., 2017). This high risk of physical health issues has shown to be a pressing concern for the development and performance of elite youth handball (Bjørndal, Ronglan, \& Andersen, 2015). Specifically, injuries and burnout appear related to a loss of motivation and interest, potentially leading to dropout from competitive handball (Bjørndal et al., 2018). Thus, because of the high risk of injury and illness, elite youth handball seems to be an appropriate and relevant context in which to explore these relationships further.

To address our present aim we tested a cross-lagged panel model (Figure 1; Little, 2013). This design allowed us to test the relationship between the variables over time, and the directionality of the relationships, and offers a more rigorous test of these relationships in comparison to crosssectional designs because you can account for previous levels of the variables (Little, 2013). In line with SDT, we hypothesized that higher levels of RPII would be related to a decrease in the satisfaction of autonomy, competence and relatedness. Moreover, we also hypothesised that higher levels of need satisfaction would be associated with a lower level of RPII.

\section{Method}

\section{Participants and Procedures}

The sample consisted of 174 (female $=115$ ) youth elite handball players from five different sport schools in Norway, which are upper secondary schools that offer training opportunities for athletes during school hours. The players were between 15 to 18 years of age (mean $(M)=$
16.8 years, standard deviation $(\mathrm{SD})=.91$ years), had played handball for an average of 7.35 years $(S D=2.12$ ), and engaged in a mean of 11.6 hours of practice per week $(\mathrm{SD}=3.60)$. Their playing experience ranged from the under-16 level to the adult elite level ( $37 \%$ had experience from youth handball only, $45 \%$ from the sub-elite level, $16 \%$ from the elite level, whilst $2 \%$ did not report their performance level). Finally, their reported experience from formalised talent development activities ranged from none to youth international team activities $(24 \%$ had no experience, $56 \%$ from regional teams, and $20 \%$ from the youth international teams).

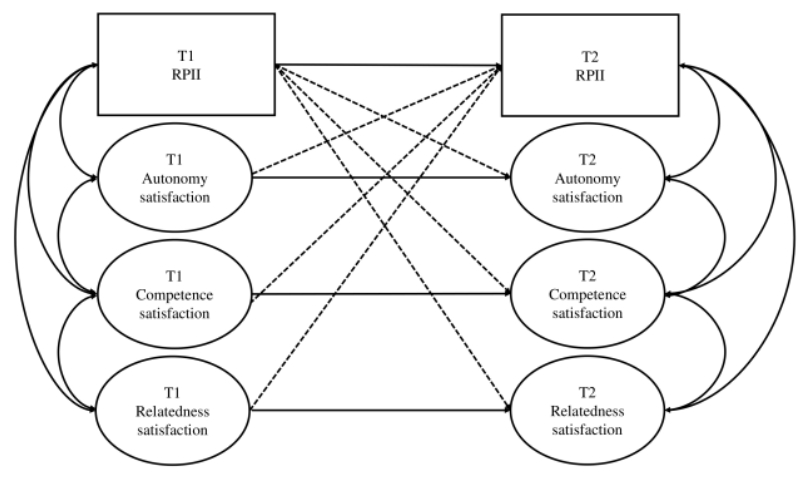

Figure 1: The hypothesized cross-lagged panel model. Note. T1 refers to time 1, and T2 refers to time 2 .

The present data is part of a larger research project investigating aspects pertaining to injuries in the youth elite handball context in Norway. The Norwegian Centre for Research Data, as well as the Ethical Review Board at the Norwegian School of Sport Sciences, approved the project prior to its commencement. All participants were informed about the study in written form as well as verbally and gave their informed consent electronically. The ethical approval allowed the participants to consent themselves, as they were above the age of 15 years, and we did not collect any sensitive health information. Participants were assured that their responses would only be available to the research team and not the coaches or the sports schools and that participation was voluntary, and consent could be withdrawn at any point.

The data employed in the present study were collected electronically through an electronic survey system (Balaguer et al., 2012)(Briteback AB). Specifically, the time 1 (T1) data were collected on a Sunday, at the start of the handball season, whilst the repeated assessment (T2) data were collected the following Sunday. A total of 231 participants were initially asked if they wanted to participate in the study, and 228 accepted the invitation. However, only 188 responded beyond the baseline measure. In addition, 14 participants did not respond to the psychological variables at $\mathrm{T} 1$ and $\mathrm{T} 2$. Probing the data indicated that these participants were dealing with serious injuries, leaving them out of training and competition completely, which is likely why they did not respond to the need satisfaction items. As they did not respond to the core variables, we elected to remove them from any further analyses in the present study, resulting in 174 participants.

An issue when conducting longitudinal studies is the aspect of temporality (Jose, 2016). It is imperative to base the temporal design on an appropriate conceptualisation of the change one aims to predict (Little, 2013; Ployhart \& Vandenberg, 2010). To the best of our knowledge, there is no agreed upon theory of change regarding basic psychological need satisfaction in sport. Some studies have found relatively little change across a competitive season (Gjesdal, Wold, \& Ommundsen, 2019), while others have 
found changes from pre to post game (Sheldon et al., 2013), or from practice to practice (Gagne, 2003). We, therefore, decided to base our temporal on previous research showing that longer time-lapses than once a week may identify fewer injury and illness incidents (Clarsen, Rønsen, Myklebust, Flørenes, \& Bahr, 2014).

There were some issues with missing data in the present study. Specifically, of a total of 174 players, 150 $(86.20 \%)$ responded at both time points, whilst 4 participants did not respond at T1 $(2.87 \%), 20$ participants did not respond at T2 (11.49\%), and 13 participants only responded to the RPII item at T2 $(7.47 \%)$. Little's missing completely at random (MCAR) test indicated that the data was not missing completely at random $\left(x^{2}=30.079 ; d f=\right.$ $13 ; \mathrm{p}<.001)$. As recommended by Enders (2010), independent t-tests with bootstrapping were conducted to examine the missing data further. Findings showed that those who only responded to the RPII item at T2 reported higher levels of RPII at T2 compared to those who responded to all items at both time points $(\mathrm{t}=-6.114 ; d f$ $=132 ; \mathrm{p}<.000 ;$ BC 96\%CI $[-3.020,-1.200] ;$ Cohen's $d$ effect size $=1.66)$. No other differences were found. To handle the missing data in a principled way we relied on the Full Information Maximum Likelihood (FIML) technique. This approach leverages all available information from the observed data to fit the statistical model (Lang \& Little, 2018). FIML is considered effective in reducing biases due to non-random missing data, offering reliable results even with a $60 \%$ missing rate (Dong \& Peng, 2013; Hallgren \& Witkiewitz, 2013).

\section{Measures}

As we were interested in the degree to which the athletes experienced an injury of health issue affecting their performance and not the injury per se, we measured perceived RPII using only one item from the Oslo Sports Trauma Research Center Questionnaire (OSTRC-Q: Clarsen, Rønsen, Myklebust, Flørenes, \& Bahr, 2014). The participants were asked to answer the question regardless of whether they experienced health problems in the past week and to select the alternative that was most appropriate for them. The item read, "To what extent has an injury, illness or other health problems affected your performance during the past week?" and was scored on a 5 -point scale $(1=$ No effect, $2=$ To a minor extent, $3=$ To a moderate extent, $4=$ To a major extent, $5=$ Did not participate at all). This scale has been validated with elite athletes previously (Clarsen et al., 2014).

Basic Psychological Need satisfaction was measured by the need satisfaction subscale of the Basic Psychological Need Satisfaction and Frustration Scale (BPNSNF: Chen et al., 2015). The players were asked about their experiences with handball during the past week. We modified the items slightly to be more reflective of the handball context. For example, the item "I feel that the people I care about also care about me" was altered to "I feel that the people I care about in handball also care about me". Moreover, these scales were part of a larger questionnaire package, disseminated to the participants every week throughout the competitive season. Therefore, in order to reduce the burden on the participants and prevent dropout, we made use of a shortened scale of 12 items. This has been shown to be valid in previous research with young athletes previously (Delrue et al., 2019). The items were scored on a 5 -point Likert scale (1 = completely disagree, $5=$ completely disagree).

Four items measured autonomy (e.g., "I feel that my decisions reflected what I really want in handball").
Confirmatory factor analyses (CFA) showed acceptable fit for $\mathrm{T} 1\left(\left(\mathrm{~S}-\mathrm{B} \mathrm{X} \mathrm{X}^{2}\right)=[\mathrm{df}=2, \mathrm{~N}=165]=5.855, \mathrm{p}<.054\right.$; CFI $=.98$, and SRMR $=.03)$ and T2 $\left(\left(\mathrm{S}-\mathrm{B} X^{2}\right)=[\mathrm{df}=2\right.$, $\mathrm{N}=143]=4.632, \mathrm{p}<.099 ; \mathrm{CFI}=.97$, and SRMR $=.03)$. The latent variable model composite reliability, denoted by rho $(\rho)$, was computed to offer an estimate of reliability (Raykov, 2009). Acceptable internal reliability was indicated for autonomy at T2 $(r h o=.77 ; 95 \% \mathrm{CI}=[.70$, $.84]$; S.E. $=.04)$, but not at $\mathrm{T} 1(r h o=.55 ; 95 \% \mathrm{CI}=[.43$, $.66]$; S.E. $=.06)$, based on a composite reliability coefficient below .60 being considered unsatisfactory (Bagozzi \& Yi, 1988).

Four items measured competence (e.g., "I felt competent to achieve my goals in handball"). The CFAs showed acceptable fit for $\mathrm{T} 1\left(\left(\mathrm{~S}-\mathrm{B} \mathrm{X}^{2}\right)=[\mathrm{df}=2, \mathrm{~N}=165]\right.$ $=14.129, \mathrm{p}<.001 ; \mathrm{CFI}=.93$, and SRMR $=.03)$ and $\mathrm{T} 2$ $\left(\left(\mathrm{S}-\mathrm{B} \mathrm{X}^{2}\right)=[\mathrm{df}=2, \mathrm{~N}=143]=7.314, \mathrm{p}<.026\right.$; CFI $=$ .98 , and SRMR $=.03)$. Furthermore, four items measured relatedness (e.g., "I felt that the people I care about in handball also care about me"). The CFAs showed acceptable fit for $\mathrm{T} 1\left(\left(\mathrm{~S}-\mathrm{B} \mathrm{X}^{2}\right)=[\mathrm{df}=2, \mathrm{~N}=165]=5.855\right.$, $\mathrm{p}<.054 ; \mathrm{CFI}=.98$, and SRMR $=.03)$ and $\mathrm{T} 2\left(\left(\mathrm{~S}-\mathrm{B} X^{2}\right)=\right.$ $[\mathrm{df}=2, \mathrm{~N}=142]=1.170, \mathrm{p}<.557 ; \mathrm{CFI}=1.00$, and SRMR $=.01$ ).

\section{Data analyses}

Mplus 7.3 software (Muthén \& Muthén, 1998-2012) was used to conduct the analyses. First, as presented above, individual CFA's were run for each of the latent variables to test the quality of these, which is a necessary first step when conduction structural equation modelling (Little, 2013). This was particularly important given that we used a shortened version of the BPNSNF. Second, using the maximum likelihood estimation with robust standard errors (MLR), we tested a cross-lagged panel model with two time points (see Figure 1). In terms of model fit, we relied on two fit indices, namely the comparative fit index (CFI) and the standardized root mean square residual (SRMR). While acknowledging that cut-off values for such fit indices are a highly debated matter among scholars (Brown \& Moore, 2012), we followed the recommendation by Little (2013), with good fit indicated by values close to or greater than CFI $=.90$ and less than .08 for SRMR, respectively. We did not rely on the root mean square error of approximation (RMSEA) for the CFAs and the structural model, as it has been shown to be biased with small sample sizes (P. J. Curran, Bollen, Chen, Paxton, \& Kirby, 2003). Furthermore, the results of the structural model were interpreted based on standardized parameter estimates, with $95 \%$ confidence intervals (CI).

We tested measurement invariance (MI) in order to establish whether our indicators measured the same latent construct across time (Byrne, 2012; Sass, 2011). For identifying and scaling the latent variables, the effects coding method was employed as a non-arbitrary method for identifying and scaling the latent variables (Little, 2013; Little, Slegers, \& Card, 2006). We conducted four CFA's with increasingly restrictive parameters; each time point separately, configural invariance (model form invariance), metric invariance (factor loading invariance), and scalar invariance (intercept invariance), respectively. Strong MI is assumed if the increasing restrictions do not significantly alter the model fit (Sass, 2011). For the test of metric invariance, we relied on the criteria of a non-significant difference in chi-square, $\triangle \mathrm{CFI}<.01, \triangle \mathrm{RMSEA}<.015$, and $\triangle$ SRMR $<.03$. For scalar invariance, we employed the criteria of a non-significant difference in chi-square, $\triangle \mathrm{CFI}<$ $.01, \triangle \mathrm{RMSEA}<.015$, and $\triangle \mathrm{SRMR}<.01$. 
Table 1. Descriptive statistics, reliability estimates and estimated correlation matrix for all variables.

\begin{tabular}{|c|c|c|c|c|c|c|c|c|c|c|}
\hline & Rho $^{1}$ & $\begin{array}{l}\text { Mean } \\
(\text { SD) }\end{array}$ & $\begin{array}{l}\text { Factor } \\
\text { scores }\end{array}$ & 2 & 3 & 4 & 5 & 6 & 7 & 8 \\
\hline 1. Autonomy T1 & $\begin{array}{c}.55(.43- \\
.67)\end{array}$ & $3.83(.55)$ & .84 & $.61 * *$ & $.62 * *$ & $.40 * *$ & $.41 * *$ & $.42 * *$ &.$\overline{-}$ & -.013 \\
\hline 2. Autonomy T2 & $\begin{array}{l}.77(.70- \\
.84)\end{array}$ & $3.88(.69)$ & .91 & & $.58 * *$ & $.74 * *$ & $.47^{* *}$ & $.57 * *$ &.$\overline{-}$ & $.23^{-}$ \\
\hline $\begin{array}{l}\text { 3. Competence } \\
\text { T1 }\end{array}$ & $\begin{array}{c}.81(.76- \\
.87)\end{array}$ & $3.76(.67)$ & .92 & & & $.64 * *$ & $.53 * *$ & $.40 * *$ & $\overline{-}$. & $-.19 *$ \\
\hline $\begin{array}{l}\text { 4. Competence } \\
\text { T2 }\end{array}$ & $\begin{array}{c}.87(.83- \\
.92)\end{array}$ & $3.77(.80)$ & .95 & & & & $.42 * *$ & $.53 * *$ & $.43^{-}$ & $.47^{-}$ \\
\hline Relatedness & $\begin{array}{c}.84(.80- \\
.89)\end{array}$ & $4.25(.67)$ & .93 & & & & & $.71 * *$ & -.12 & -.08 \\
\hline $\begin{array}{ll}\text { 6. } & \text { Relatedness } \\
\text { T2 } & \end{array}$ & $\begin{array}{c}.86(.82- \\
.90)\end{array}$ & $4.21(.67)$ & .94 & & & & & & $.27^{-}$ & -.11 \\
\hline 7. RPII & - & $2.05(1.08)$ & - & & & & & & & $.52 * *$ \\
\hline 8. RPII & - & $2.06(1.26)$ & - & & & & & & & \\
\hline
\end{tabular}

Note: $* \mathrm{p} \leq .05, * * \leq .01 ;{ }^{1}$ confidence intervals for Rho put in parentheses, RPII refers to reduced performance due to injury or illness.

Table 2. Model fit indices for longitudinal factorial invariances for autonomy, competence and relatedness needs.

\begin{tabular}{|c|c|c|c|c|c|c|c|c|c|c|c|c|}
\hline & Model & $x^{2}$ & $d f$ & $p$ & RMSEA & $\triangle \mathrm{RMSEA}$ & $\begin{array}{l}\text { RMSEA } \\
90 \% \mathrm{CI} \\
\end{array}$ & SRMR & $\Delta \mathrm{SRMR}$ & CFI & $\Delta \mathrm{CFI}$ & Retained? \\
\hline \multirow[t]{3}{*}{ Autonomy } & $\begin{array}{l}1 . \\
\text { Configural } \\
\text { model }\end{array}$ & 23.589 & 15 & .0724 & .057 & - & $\begin{array}{l}.000- \\
.100\end{array}$ & .050 & - & .966 & - & - \\
\hline & $\begin{array}{l}\text { 2. Metric } \\
\text { model }\end{array}$ & 27.743* & 18 & . 0661 & .056 & .001 & $\begin{array}{l}.000- \\
.095\end{array}$ & .074 & .027 & .962 & .004 & Yes \\
\hline & $\begin{array}{l}\text { 3. Scalar } \\
\text { model }\end{array}$ & 43.064 & 21 & .0031 & .078 & .022 & $\begin{array}{l}.044- \\
.111 \\
\end{array}$ & . 071 & .003 & .914 & .048 & No \\
\hline \multirow[t]{3}{*}{ Competence } & $\begin{array}{l}1 . \\
\text { Configural } \\
\text { model }\end{array}$ & 30.834 & 15 & .0092 & .078 & - & $\begin{array}{l}.038- \\
.117\end{array}$ & .044 & - & .971 & - & - \\
\hline & $\begin{array}{l}\text { 2. Metric } \\
\text { model }\end{array}$ & $31.315^{*}$ & 18 & . 0265 & .065 & .013 & $\begin{array}{l}.022- \\
.103\end{array}$ & .046 & .002 & .975 & .004 & Yes \\
\hline & $\begin{array}{l}\text { 3. Scalar } \\
\text { model }\end{array}$ & $35.035 *$ & 21 & .0280 & .062 & .003 & $\begin{array}{l}.021- \\
.097\end{array}$ & .049 & .003 & .974 & .001 & Yes \\
\hline \multirow[t]{3}{*}{ Relatedness } & $\begin{array}{l}1 . \\
\text { Configural } \\
\text { model }\end{array}$ & 14.882 & 15 & .4599 & .000 & - & $\begin{array}{l}.000- \\
.071\end{array}$ & .029 & - & 1.00 & - & - \\
\hline & $\begin{array}{l}\text { 2. Metric } \\
\text { model }\end{array}$ & $16.135^{*}$ & 18 & .5831 & .000 & 0 & $\begin{array}{l}.000- \\
.060\end{array}$ & .050 & .021 & 1.00 & 0 & Yes \\
\hline & $\begin{array}{l}\text { 3. Scalar } \\
\text { model }\end{array}$ & $17.555 *$ & 21 & . 6770 & .000 & 0 & $\begin{array}{l}.000- \\
.052\end{array}$ & .053 & .003 & 1.00 & 0 & Yes \\
\hline
\end{tabular}

Note: Retained? refers to whether the model is retained based on the fit indices not having changed significantly from the previous model, $*=$ non-significant difference in chi-square values.

\section{Results}

Table 1 presents descriptive statistics, composite reliability coefficients, factor scores and correlations between all variables. The participant generally reported high levels of basic need satisfaction, particularly relatedness. Moreover, a larger range was seen in RPII at both time points. In terms of the latent variable correlation matrix, the results revealed an expected pattern of correlations between the variables.

Fit indices for the increasingly strict models for all three needs are presented in Table 2 . The configural model for autonomy showed acceptable fit (CFI $=.966$ and RMSEA $=.057[.000-.100]$, and SRMR $=.050)$, and the metric did not present significantly different fit, and the chi-square difference test was non-significant $\left(\Delta x^{2}(3)=4.301, \mathrm{p}=\right.$ .231). However, the scalar model did appear to be significantly different from the metric model. Strong invariance was therefore not inferred for autonomy, and combined with the low composite reliability coefficient, we elected to exclude autonomy from any further analyses.

The configural model for competence showed acceptable fit (CFI $=.971$ and RMSEA $=.078[.038-.117]$, and SRMR $=.044)$, and the metric $\left(\Delta x^{2}(3)=.711, \mathrm{p}=\right.$ $.871)$ and scalar models $\left(\Delta x^{2}(3)=3.739, \mathrm{p}=.291\right)$ did not present significantly different fit. Thus, strong invariance for competence was inferred. Similar results were reported for relatedness. Specifically, the configural model showed good fit, and the metric $\left(\Delta x^{2}(3)=1.409, \mathrm{p}\right.$ $=.703)$ and scalar $\left(\Delta x^{2}(3)=.977, \mathrm{p}=.807\right)$ models did not present significantly different fit, reflecting strong invariance for relatedness. 
The structural model (see Figure 2) showed good fit $\left(\left(\mathrm{S}-\mathrm{B} \mathrm{X}^{2}\right)=[\mathrm{df}=130, \mathrm{~N}=174]=182.327, p<.0017\right.$, and SRMR $=.08)$. Competence $(\beta=.64,95 \% \mathrm{CI}: .51, .76)$, relatedness $(\beta=.77,95 \% \mathrm{CI}: .66, .88)$ and RPII $(\beta=.51$, 95\%CI: .37, .66) showed moderate temporal stability. As hypothesized, when accounting for previous levels of the needs, RPII was negatively related to competence $(\beta=-.20$, 95\%CI: $-.35,-.05)$ and relatedness $(\beta=-.16,95 \% \mathrm{CI}:-.30$, $-.01)$. Contrary to our hypotheses, the paths from competence and relatedness to RPII, when accounting for previous levels of RPII, were non-significant.

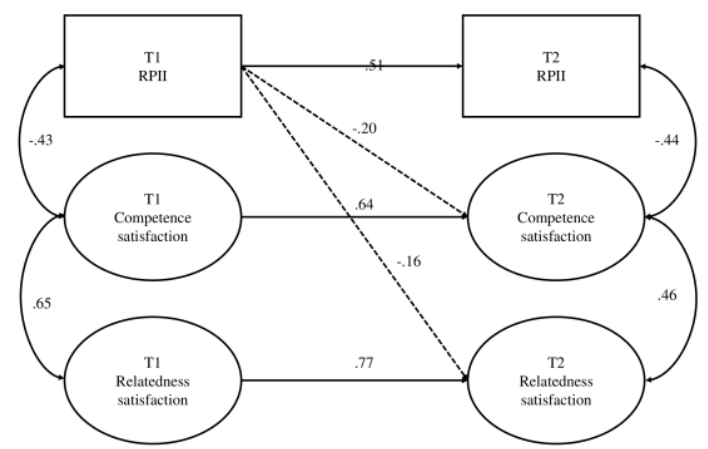

Figure 2: The structural model. Note. T1 refers to time 1, and $\mathrm{T} 2$ refers to time 2 . To maintain clarity, only significant parameters are presented in the model.

\section{Discussion}

Building on previous research (Sheldon et al., 2013), the present findings show that higher levels of RPII were associated with lower levels of competence need satisfaction. This suggests that even if a perceived reduction in performance is due to an injury or illness, i.e. an external event, and not necessarily the players' ability per se, it may hold implications for their sense of competence. Competence is highly emphasized in the sporting context and appears to be a major factor related to dropout (Balish, McLaren, Rainham, \& Blanchard, 2014). Additionally, as competence seems closely related to youth athletes' sense of general self-esteem (Gjesdal, Appleton, \& Ommundsen, 2017; Kipp \& Weiss, 2013), this may explain why previous research has found a strong link between experiencing an injury and a reduction in athletes' self-esteem (Ardern et al., 2013; Smith, 1996). Thus, experiencing RPII may have dire consequences for elite youth handball players, by way of a reduced sense of competence.

The link between RPII and relatedness, although not as strong as the relationship between RPII and competence, is interesting. This, too, builds on the findings of Sheldon et al. (2013), indicating that the players' need for relatedness is somewhat contingent on their performance, even when performance is reduced due to some external event. However, SDT explicitly states that true satisfaction of relatedness comes from relationships that are based on an intrinsic caring for each other and not extrinsic contingencies, such as performance (Ryan \& Deci, 2017). It, therefore, seems that we may have tapped into some type of conditional relatedness, which would be more reflective of a controlling social practice rather than actual need satisfaction. It would be interesting to probe youth elite athletes' view of relatedness in the sporting context, to investigate this issue further. However, there could also be a simpler explanation for this finding, in that experiencing injury or illness may have resulted in less contact with important others in the sporting context, or less energy to engage.

According to previous research, getting injured is related to a number of psychological constructs, showing that this experience can have a substantial psychological effect on athletes (Ardern et al., 2013; Smith, 1996). However, these studies have not attempted to explain the mechanisms by which this experience is linked to these various outcomes. The present findings suggest that a reduced sense of performance and its relationship to basic psychological need satisfaction may be part of that mechanism. This is something that should receive empirical attention moving forward because it can offer valuable information on how to lessen the impact injuries may have on athletes. This is crucial in sports such as handball, given the high risk of injury (Bjørndal et al., 2018; Møller et al., 2017).

Competence and relatedness satisfaction at T1 was not related to T2 RPII, suggesting that the level of need satisfaction previously had no bearing on this type of reduced performance. We do not know if this is because competence and relatedness were not associated with experiencing an actual injury or illness or that they were not related to experiencing injury or illness as affecting performance. In the case of the former, the finding is contrary to that of Li et al. (2019), who found that basic psychological need satisfaction was a negative predictor of injuries. In the case of the latter, it is somewhat inconsistent with the findings of Sheldon et al. (2013), who reported that pre-game autonomy and competence were predictive of aspects of basketball performance in that given game. Furthermore, they found relatedness to be negatively related to performance. Differences in how performance was measured can explain the discrepancies in findings between Sheldon et al. (2013) and the present study. Sheldon and colleagues employed an objective measure of performance whilst we looked at perceived reduced performance due to injury or illness. It is conceivable that basic psychological need satisfaction can influence performance through intrinsic motivation, positive mood and cognitive efficiency if the performance is within the person's control (Ryan, 1995). However, it may be less likely to make an impact when the performance is affected by an external factor such as injury or illness. Furthermore, it should be noted that the participants reported high scores on all three basic needs, indicating that they generally experienced need satisfaction. It could be that this relationship would emerge in a sample where the need satisfaction was less positively skewed.

Researchers have argued that basic psychological need satisfaction may be important when assisting athletes in making a full recovery from an injury or illness (Ardern et al., 2013; Podlog \& Eklund, 2007). This is interesting in light of the present findings, which suggest that a reduction in need satisfaction may occur if athletes experience this type of setback as a reduction in performance, even in the short term. It, therefore, seems imperative that coaches and sport psychologists are aware of the potential implications that RPII can have on players. Specifically, players' who are suffering from an injury or illness should immediately receive extra support for basic psychological needs to prevent a potential reduction.

\section{Limitations, strengths and conclusions}

The present study has its limitations. First, the relatively low number participants, and the issue with missing data, limited our opportunity to create more complex models. Second, we measured perceived RPII, and therefore do not 
know how this corresponds to more objective measures of performance. Third, a cross-lagged panel design allows for predicting residual change but cannot establish causality. Along those lines, this design has been critiqued for not capturing the right type of stability, yet this seems most pertinent with trait-like constructs (Hamaker, Kuiper, \& Grasman, 2015). Moreover, the use of only two time points precludes modelling the trajectories over time. Fourth, our autonomy measure was not invariant across time, which did not allow us to test its relationship with RPII. Additionally, we used a shortened questionnaire to measure the three needs. Moreover, we did not distinguish between injury and illness, preventing comparisons between the two categories. Future research should investigate whether there are differences between injury and illness and between different types of injuries and illnesses. Finally, although our findings suggest that an aspect other than the psychosocial environment may predict basic psychological need satisfaction, we know little about this influence relative to important aspects of the psychosocial environment. We, therefore, urge researchers to look at such aspects in conjunction with the coach and parent support in order to gain a greater understanding of how we can support youth athletes' need satisfaction.
Notwithstanding the aforementioned limitations, the present study has several strengths. The main strength is the formal investigation of the relationship between RPII and basic psychological need satisfaction and the use of a cross-lagged panel design. Furthermore, though the sample is relatively small, it is representative of the broader youth elite handball population in Norway. Finally, investigating the basic psychological needs separately allowed us to discern their unique relationship with RPII, which offers valuable information for both researchers and practitioners.

To conclude, the present study contributes new knowledge on the relationship between RPII and basic psychological needs. Findings suggest that basic psychological need satisfaction is related to perceptions of one's own performance, as RPII negatively predicted competence and relatedness satisfaction across one week. This underlines the importance of investigating need satisfaction in relation to other aspects than just the psychosocial environment in sport and the potential implications of physical health issues for the motivation of youth elite handball players.

\section{Referencer}

Adie, J. W., Duda, J. L., \& Ntoumanis, N. (2012). Perceived coach-autonomy support, basic need satisfaction and the well-and ill-being of elite youth soccer players: A longitudinal investigation. Psychology of Sport and Exercise, 13(1), 51-59.

Andersson, S. H., Bahr, R., Clarsen, B., \& Myklebust, G. (2018). Risk factors for overuse shoulder injuries in a mixed-sex cohort of 329 elite handball players: previous findings could not be confirmed. British journal of sports medicine, 52(18), 1191-1198.

Ardern, C. L., Taylor, N. F., Feller, J. A., \& Webster, K. E. (2013). A systematic review of the psychological factors associated with returning to sport following injury. British journal of sports medicine, 47(17), 1120-1126.

Asker, M., Brooke, H. L., Waldén, M., Tranaeus, U., Johansson, F., Skillgate, E., \& Holm, L. W. (2018). Risk factors for, and prevention of, shoulder injuries in overhead sports: a systematic review with best-evidence synthesis. British journal of sports medicine, 52(20), 1312-1319.

Bagozzi, R. P., \& Yi, Y. (1988). On the evaluation of structural equation models. Journal of the academy of marketing science, 16(1), 74-94.

Balaguer, I., González, L., Fabra, P., Castillo, I., Mercé, J., \& Duda, J. L. (2012). Coaches' interpersonal style, basic psychological needs and the well-and ill-being of young soccer players: A longitudinal analysis. Journal of sports science, 30(15), 1619-1629.

Balish, S. M., McLaren, C., Rainham, D., \& Blanchard, C. (2014). Correlates of youth sport attrition: A review and future directions. Psychology of Sport and Exercise, 15(4), 429-439.

Bjørndal, C. T., Andersen, S. S., \& Ronglan, L. T. (2018). Successful and unsuccessful transitions to the elite level: The youth national team pathways in Norwegian handball. International Journal of Sports Science \& Coaching, 13(4), 533-544.

Bjørndal, C. T., Ronglan, L. T., \& Andersen, S. S. (2015). Talent development as an ecology of games: a case study of Norwegian handball. Sport, Education and Society, 22(7), 864-877.

Brown, T. A., \& Moore, M. T. (2012). Confirmatory factor analysis. In R. H. Hoyle (Ed.), Handbook of structural equation modeling (pp. 361-379). New York, NY: Guilford Press.

Byrne, B. M. (2012). Structural equation modeling with Mplus: Basic concepts, applications, and programming. New York, NY: Routledge.

Chen, B., Vansteenkiste, M., Beyers, W., Boone, L., Deci, E. L., Van der KaapDeeder, J., . . . Mouratidis, A. (2015). Basic psychological need satisfaction, need frustration, and need strength across four cultures. Motivation and Emotion, 39(2), 216-236.

Clarsen, B., Rønsen, O., Myklebust, G., Flørenes, T. W., \& Bahr, R. (2014). The Oslo Sports Trauma Research Center questionnaire on health problems: a new approach to prospective monitoring of illness and injury in elite athletes. British journal of sports medicine, 48(9), 754-760.
Curran, P. J., Bollen, K. A., Chen, F., Paxton, P., \& Kirby, J. B. (2003). Finite sampling properties of the point estimates and confidence intervals of the RMSEA. Sociological Methods \& Research, 32(2), 208-252.

Curran, T., Hill, A. P., Ntoumanis, N., Hall, H. K., \& Jowett, G. E. (2016). A threewave longitudinal test of self-determination theory's mediation model of engagement and disaffection in youth sport. Journal of Sport and Exercise Psychology, 38(1), 15-29.

Deci, E. L., \& Ryan, R. M. (2000). The" what" and" why" of goal pursuits: Human needs and the self-determination of behavior. Psychological inquiry, 11(4), 227-268.

Delrue, J., Reynders, B., Broek, G. V., Aelterman, N., De Backer, M., Decroos, S., van Puyenbroeck, S. (2019). Adopting a helicopter-perspective towards motivating and demotivating coaching: A circumplex approach. Psychology of Sport and Exercise, 40, 110-126.

Dong, Y., \& Peng, C.-Y. J. (2013). Principled missing data methods for researchers. SpringerPlus, 2(1), 222.

Enders, C. K. (2010). Applied Missing Data Analysis. New York, NY: The Guilford Press.

Gagne, M. (2003). Autonomy support and need satisfaction in the motivation and well-being of gymnasts. Journal of Applied Sport Psychology, 15(4), 372-390.

Gjesdal, S., Appleton, P. R., \& Ommundsen, Y. (2017). Both the "what" and "why" of youth sports participation matter; a conditional process analysis. Frontiers in Psychology, 8, 659 .

Gjesdal, S., Wold, B., \& Ommundsen, Y. (2019). Promoting additional activity in youth soccer: a half-longitudinal study on the influence of autonomysupportive coaching and basic psychological need satisfaction. Journal of sports sciences, 37(3), 268-276.

Hallgren, K. A., \& Witkiewitz, K. (2013). Missing data in alcohol clinical trials: a comparison of methods. Alcoholism: Clinical and Experimental Research, 37(12), 2152-2160.

Hamaker, E. L., Kuiper, R. M., \& Grasman, R. P. (2015). A critique of the crosslagged panel model. Psychological methods, 20(1), 102.

Jose, P. E. (2016). The merits of using longitudinal mediation. Educational Psychologist, 51(3-4), 331-341.

Kipp, L. E., \& Weiss, M. R. (2013). Social influences, psychological need satisfaction, and well-being among female adolescent gymnasts. Sport, Exercise, and Performance Psychology, 2(1), 62.

Lang, K. M., \& Little, T. D. (2018). Principled missing data treatments. Prev Sci, 19(3), 284-294.

Li, C., Ivarsson, A., Lam, L. T., \& Sun, J. (2019). Basic Psychological Need Satisfaction and Frustration, Stress, and Sports Injury among University Athletes: A Four-Wave Prospective Survey. Frontiers in Psychology, 10,665 .

Little, T. D. (2013). Longitudinal Structural Equation Modeling. New York, NY: The Guilford Press. 
Little, T. D., Slegers, D. W., \& Card, N. A. (2006). A non-arbitrary method of identifying and scaling latent variables in SEM and MACS models. Structural Equation Modeling, 13(1), 59-72.

Luteberget, L. S., \& Spencer, M. (2017). High-intensity events in international women's team handball matches. International journal of sports physiology and performance, 12(1), 56-61.

Mageau, G. A., \& Vallerand, R. J. (2003). The coach-athlete relationship: A motivational model. Journal of sports science, 21(11), 883-904.

Muthén, L. K., \& Muthén, B. O. (1998-2012). Mplus User's Guide: Statistical Analysis with Latent Variables. In. Los Angeles, CA: Muthén \& Muthén.

Myklebust, G. (2014). Between basketball and rugby: The risk of injury in handball. Aspetar Sports Medicine Journal, 138-141.

Møller, M., Nielsen, R., Attermann, J., Wedderkopp, N., Lind, M., Sørensen, H., \& Myklebust, G. (2017). Handball load and shoulder injury rate: a 31-week cohort study of 679 elite youth handball players. British journal of sports medicine, 51(4), 231-237.

Ployhart, R. E., \& Vandenberg, R. J. (2010). Longitudinal research: The theory, design, and analysis of change. Journal of management, 36(1), 94-120.

Podlog, L., \& Eklund, R. C. (2007). The psychosocial aspects of a return to sport following serious injury: a review of the literature from a selfdetermination perspective. Psychology of Sport and Exercise, 8(4), 535566.

Póvoas, S. C., Ascensão, A. A., Magalhães, J., Seabra, A. F., Krustrup, P., Soares, J. M., \& Rebelo, A. N. (2014). Physiological demands of elite team handball with special reference to playing position. The Journal of Strength \& Conditioning Research, 28(2), 430-442.
Quested, E., Bosch, J. A., Burns, V. E., Cumming, J., Ntoumanis, N., \& Duda, J. L. (2011). Basic psychological need satisfaction, stress-related appraisals, and dancers' cortisol and anxiety responses. Journal of Sport and Exercise Psychology, 33(6), 828-846.

Raykov, T. (2009). Evaluation of scale reliability for unidimensional measures using latent variable modeling. Measurement and Evaluation in Counseling and Development, 42(3), 223-232.

Ryan, R. M. (1995). Psychological needs and the facilitation of integrative processes. Journal of personality, 63(3), 397-427.

Ryan, R. M., \& Deci, E. L. (2017). Self-Determination Theory. New York, NY: The Guilford Press.

Sass, D. (2011). Testing measurement invariance and comparing latent factor means within a confirmatory factor analysis framework. Journal of Psychoeducational Assessment, 29(4), 347-363. doi:10.1177/0734282911406661

Sheldon, K. M., Zhaoyang, R., \& Williams, M. J. (2013). Psychological needsatisfaction, and basketball performance. Psychology of Sport and Exercise, 14(5), 675-681.

Smith, A. M. (1996). Psychological impact of injuries in athletes. Sports Medicine, 22(6), 391-405

Wiese-Bjornstal, D. M. (2010). Psychology and socioculture affect injury risk, response, and recovery in high-intensity athletes: a consensus statement. Scandinavian Journal of Medicine \& Science in Sports, 20, 103-111.

Williams, J. M., \& Andersen, M. B. (1998). Psychosocial antecedents of sport injury: Review and critique of the stress and injury model. Journal of Applied Sport Psychology, 10(1), 5-25. doi:10.1080/10413209808406375 